\title{
Factors associated with knowledge of a Good Samaritan Law among young adults who use prescription opioids non-medically
}

\author{
Tristan I. Evans ${ }^{1}$, Scott E. Hadland ${ }^{2,3,4}$, Melissa A. Clark ${ }^{1,5}$, Traci C. Green ${ }^{1,6,7}$ and Brandon D. L. Marshall ${ }^{*}$
}

\begin{abstract}
Background: To date, no studies have examined the extent of knowledge and perceptions of Good Samaritan Laws (GSLs) among young adults who engage in non-medical prescription opioid (NMPO) use. We sought to determine awareness of and factors associated with knowledge of Rhode Island's Good Samaritan Law (RIGSL) among young adult NMPO users.

Findings: We compared the sociodemographic and overdose-related characteristics of participants who were aware and unaware of the RIGSL and determined independent correlates of knowledge of the RIGSL via modified stepwise logistic regression. Among 198 eligible participants, $15.7 \%$ were black, $62.1 \%$ white, and $20.7 \%$ mixed or other race. The mean age was $24.5(\mathrm{SD}=3.2)$ and $129(65.2 \%)$ were male. Fewer than half (45.5\%) were aware of the RIGSL; nonetheless, the majority (95.5\%) reported a willingness to call 911 in the event of an overdose. Knowledge of the RIGSL was associated with older age, white race, a history of incarceration, a history of injection drug use, lifetime heroin use, ever witnessing or experiencing an overdose, having heard of naloxone, knowledge of where to obtain naloxone, and experience administering naloxone (all $p<0.05$ ). In the final explanatory regression model, lifetime injection drug use, having heard of naloxone, and knowledge of where to obtain naloxone were independently associated with awareness of the RIGSL.

Conclusions: Fewer than half of NMPO users surveyed knew of the RIGSL. Targeted harm reduction education is needed to address a vulnerable population of NMPO users who have not initiated injection drug use and are unaware of naloxone. Additional research is needed to determine how the effectiveness of GSLs could be improved to prevent overdose deaths among young adults.
\end{abstract}

Keywords: Good Samaritan Law, Opioid, Non-medical prescription opioid, Young adult, Overdose

\section{Introduction}

Since the early 2000s, non-medical prescription opioid (NMPO) use and heroin use have resulted in dramatically escalating rates of unintentional drug overdose across the USA $[1,2]$. In response to the ongoing nationwide opioid epidemic, a number of US states have implemented harm reduction programs and legislative policies focused on reducing the occurrence of fatal opioid overdose, including prescription monitoring programs, laws restricting new prescriptions for opioid medications, training programs for opioid users to

\footnotetext{
* Correspondence: brandon_marshall@brown.edu

'Department of Epidemiology, Brown University School of Public Health, 121

South Main Street, Box G-S-121-2, Providence, RI 02912, USA

Full list of author information is available at the end of the article
}

recognize overdose, and equipping first responders and community outreach organizations with naloxone [3-5]. As of 2015, 34 US states and the District of Columbia had also enacted limited opioid amnesty laws [6]. The objective of such laws is to encourage persons who witness an overdose to contact emergency personnel, even if there are controlled substances at the scene. Rhode Island's Good Samaritan Overdose Prevention Act, R.I. Gen. Laws $\$ 21-28.8-4$ (2012), first enacted in 2012 and reinstated in 2016, grants limited legal immunity to anyone who seeks or receives medical assistance for a drug-related overdose or medical emergency, unless that person is involved with the manufacture and/or distribution of controlled substances. Specifically, the law protects "Any person who, in good faith, without 
malice and in the absence of evidence of an intent to defraud seeks medical assistance for someone experiencing a drug overdose or other drug-related medical emergency shall not be charged or prosecuted for any crime under RIGL 21-28 or 21-28.5, except for a crime involving the manufacture or possession with the intent to manufacture a controlled substance or possession with intent to deliver a controlled substance, if the evidence for the charge was gained as a result of the seeking of medical assistance" [7]. Notably, the 2016 version of the law provides immunity to individuals on probation or parole (i.e., seeking medical assistance in the event of an overdose is not a violation of the terms of probation/parole).

Young adults who engage in NMPO use are a highrisk subpopulation of opioid users [8, 9]. They are often in the process of developing long-lasting and potentially life-altering patterns of polysubstance and opioid use; furthermore, young adults who engage in casual experimentation with NMPO use may transition to heroin and injection drug use [10-12]. Many harm reduction services, including syringe exchange and overdose education programs, have primarily targeted adult and/or NMPO users who use heroin and/ or inject drugs [3, 13-18]. Therefore, young opioid users who are experimenting with NMPO use are at high risk for overdose but may have received less harm reduction education and, as a result, may not know how to react to an overdose and may be unaware of the legal protections afforded by Good Samaritan Laws (GSLs) [19].

Frequently skeptical of authority (in light of the often punitive legal consequences associated with heroin and opioid possession), young adults also face perceived and systemic deterrents that may prevent them from contacting emergency personnel in the event of an opioid overdose [20]. To date, no studies have examined the extent of knowledge and perceptions of GSLs among young adult NMPO users. This study represents an initial assessment of the awareness of Rhode Island's GSL (RIGSL), R.I. Gen. Laws \$21-28.8-4 (2012), among 18-29-year-old NMPO users. Due to the socially and legally sensitive nature of the raw data, the minimum eligible age (18 years) was selected in order to include the perspectives of the youngest possible adults able to autonomously provide legal consent (in the state of Rhode Island) to participate in a sensitive public health research study. To be consistent with previously published research $[21,22]$, we defined the maximum age limit for the term "young adult" to be 29 years of age. The primary objective of the analysis was to assess the sociodemographic and behavioral factors associated with knowledge of the RIGSL.

\section{Methods}

Participants were recruited from January 2015 through February 2016 through online venues (e.g., Craigslist), bus advertisements, word of mouth, flyers, and referrals. Eligible participants were Rhode Island (RI) residents between the ages of 18 and 29 who had engaged in NMPO use within 30 days prior to their interview. NMPO use was defined as consuming a prescription opioid that was not prescribed by a licensed medical provider, or as using a prescription opioid with a different mode of administration (e.g., snorted, injected) or dosage than was prescribed. Surveys included questions about drug-related risk behavior, sexual history, employment and housing status, and NMPO and polysubstance use. A trained interviewer administered all survey questions except those related to injection drug use, which were administered via computer-assisted personal interviewing (CAPI). Participants received \$25 upon completing the hour-long survey. Between January 2015 and June 2015, we attempted to recruit participants through respondent-driven sampling (RDS). The RDS approach was terminated in June 2015 due to the limited referral of eligible participants from their peers who completed the survey; no other peer drug users were involved in the recruitment of study participants.

This study received approval from a research ethics committee, the Brown University Institutional Review Board (IRB \#1403001006), and conforms to the standards outlined in the Declaration of Helsinki. Participants voluntarily signed informed consent forms prior to completing a confidential survey.

The primary outcome relevant to this analysis was: "Have you ever heard of Rhode Island's Good Samaritan Law?" Descriptive statistics and frequencies were used to compare the characteristics of the participants who were aware and unaware of the RIGSL. Pearson's $\chi^{2}$ tests and Fisher's exact tests (for any cell counts $<5$ ) were used to determine associations between knowledge of the RIGSL and the variables listed in Table 1, which are related to injection drug use, heroin and NMPO use, experienced and witnessed opioid overdose, and naloxone access and harm reduction knowledge. We also assessed the willingness of participants to recruit emergency services by asking "Would you call 911 if you or someone you knew was overdosing, even if drugs were present at the scene?" prior to asking them if they were aware of the RIGSL. Finally, among participants who had overdosed in the last 6 months, we examined the actual actions that bystanders had taken to mitigate instances of opioid overdose (e.g., calling 911, administering naloxone).

We used a modified backward stepwise regression procedure $[23,24]$ to build an explanatory multivariate model and to identify variables independently correlated with knowledge of the RIGSL. In brief, variables listed in 
Table 1 Factors associated with knowledge of the RIGSL among young adult NMPO users $(n=198)$

\begin{tabular}{lllll}
\hline Knowledge of Rhode Island's & $\begin{array}{l}\text { Total } \\
n(\%)\end{array}$ & $\begin{array}{l}\text { Aware } \\
n(\%)\end{array}$ & $\begin{array}{l}\text { Unaware } \\
n(\%)\end{array}$ & $\begin{array}{l}p \\
\text { value }\end{array}$ \\
\hline Mean age (years, SD) & $198(100)$ & $\begin{array}{l}25.3 \\
(2.96)\end{array}$ & $\begin{array}{l}23.9 \\
(3.32)\end{array}$ & $0.003^{a}$ \\
& & & &
\end{tabular}

Sex

$\begin{array}{lllll}\text { Male } & 129(65.2) & 64(49.6) & 65(50.4) & 0.145 \\ \text { Female } & 69(34.8) & 26(37.7) & 43(62.3) & \end{array}$

Ethnicity

$\begin{array}{lllll}\text { Not Hispanic or Latino } & 170(85.9) & 77(45.3) & 93(54.7) & 0.911 \\ \text { Hispanic or Latino } & 28(14.1) & 13(46.4) & 15(53.6) & \end{array}$
Race

Black, African, Haitian, $\quad 31(15.7) \quad 9(29.0) \quad 22(71.0) \quad 0.012$ or Cape Verdean

White $\quad 123(62.1) \quad 66(53.7) \quad 57(46.3)$

Aggregated "all other races" 41 (20.7) 14 (34.1) 27 (65.9)

Education

$\begin{array}{lllll}\text { Some high school or less } & 23(11.6) & 8(34.8) & 15(65.2) & 0.558^{b} \\ \text { Finished high school or GED } & 75(37.9) & 34(45.3) & 41(54.7) \\ \text { Some college } & 74(37.4) & 35(47.3) & 39(52.7) \\ \text { Trade or technical school } & 7(3.5) & 5(71.4) & 2(28.6) \\ \text { College or university degree } & 19(9.6) & 8(42.1) & 11(57.9)\end{array}$

History of incarceration

Yes

No

$73(36.9) \quad 52(55.9) \quad 41(44.1) \quad 0.008$

$105(53.0) \quad 38(36.2) \quad 67(63.8)$

History of homelessness

$\begin{array}{lllll}\text { Yes } & 108(54.5) & 57(52.8) & 51(47.2) & 0.034 \\ \text { No } & 90(45.5) & 33(36.7) & 57(63.3) & \\ \text { Lifetime injection drug use } & & & & \\ \text { Yes } & 59(29.8) & 43(72.9) & 16(27.1) & <0.001 \\ \text { No } & 138(69.7) & 46(33.3) & 92(66.7) & \end{array}$

Lifetime heroin use

Yes

No

Ever witnessed an overdose

Yes

No

Ever experienced an overdose

Yes

No

Have you ever heard of Narcan $^{\mathrm{TM}}$, otherwise known as naloxone?

$\begin{array}{lllll}\text { Yes } & 120(60.6) & 75(62.5) & 45(37.5) & <0.001 \\ \text { No } & 78(39.4) & 15(19.2) & 63(80.8) & \end{array}$

Table 1 Factors associated with knowledge of the RIGSL among young adult NMPO users $(n=198)$ (Continued)

Do you know where to buy

or obtain Narcan ${ }^{\mathrm{TM}}$ ?

$\begin{array}{lllll}\text { Yes } & 82(41.4) & 60(73.2) & 22(26.8) & <0.001 \\ \text { No } & 116(58.6) & 30(25.9) & 86(74.1) & \end{array}$

Have you ever administered

Narcan $^{\text {TM }}$ to someone you

thought was overdosing?

\begin{tabular}{|c|c|c|c|}
\hline Yes & 21 (10.6) & $16(76.2)$ & $5(23.8)$ \\
\hline No & 177 (89.4) & $74(41.8)$ & $\begin{array}{l}103 \\
(58.2)\end{array}$ \\
\hline
\end{tabular}

Would you call 911 in the event of an overdose, even if there were drugs at the scene?

\begin{tabular}{lllll} 
Yes & $189(95.5)$ & $87(46.0)$ & 102 & $0.729^{b}$ \\
& & & $(54.0)$ & \\
No & $8(4.0)$ & $3(37.5)$ & $5(62.5)$ & \\
\hline
\end{tabular}

Welch's $t$ test

bFisher's exact test

Table 1 with $p<0.20$ were included in the initial model (variables in Table 2 were not considered due to low response counts). The covariate with the highest type III $p$ value was eliminated in subsequent rounds of regression. The model with the lowest Akaike information criterion (AIC) was selected as the final model. $\mathrm{R}$ version 3.2.3(C) 2015 was used for all statistical analysis, and all $p$ values were two-sided.

\section{Results}

Out of 200 total recruited participants, 198 (99 \%) answered the question "have you ever heard of Rhode Island's Good Samaritan Law?" and were included in the analysis. The mean age of the sample was 24.5 years ( $\mathrm{SD}=3.2), 129(65.2 \%)$ were male, and $14.1 \%$ identified their ethnicity as Hispanic or Latino. In addition, the eligible sample was 15.7 \% black (African American or of African, Haitian, or Cape Verdean descent), $62.1 \%$ white, and $20.7 \%$ were of mixed or other race.

Among eligible participants, 90 (45.5\%) reported awareness of the RIGSL. Knowledge of the RIGSL varied by race: $53.7 \%$ of white, $29.0 \%$ of black, and $34.1 \%$ of other/mixed race participants reported being aware of the RIGSL $(p=0.012)$. Other sociodemographic factors associated with awareness of the RIGSL included older age, prior incarceration, and history of homelessness (see Table 1). A sub-analysis of drug use behaviors by race showed that white participants had the highest prevalence of lifetime heroin use (61.8 versus $11.1 \%$ for black and mixed/other race participants, $p<0.001$ ), lifetime injection drug use (44.3 versus $5.6 \%$ for black and mixed/other race participants, $p<0.001$ ), and 
Table 2 Responses to recent overdoses and knowledge of the RIGSL among young adult NMPO users who reported experiencing an overdose in the past 6 months $(n=21)$

\begin{tabular}{llll}
\hline Knowledge of Rhode Island's GSL & $\begin{array}{l}\text { Total } \\
n(\%)^{\mathrm{a}}\end{array}$ & $\begin{array}{l}\text { Aware } \\
n(\%)\end{array}$ & $\begin{array}{l}\text { Unaware } \\
n(\%)\end{array}$ \\
\hline
\end{tabular}

The last time you overdosed, were you alone?

$\begin{array}{llll}\text { Yes } & 4(19.0) & 1(25.0) & 3(75.0) \\ \text { No } & 17(81.0) & 13(76.5) & 4(23.5)\end{array}$

Did someone call 911 the last time you overdosed?

Yes

No

$\begin{array}{lll}6(28.6) & 6(100.0) & 0(0.0) \\ 11(52.4) & 7(63.6) & 4(36.4)\end{array}$

The last time you overdosed were you taken to a hospital?

Yes

No

The last time you overdosed, did someone administer naloxone?

$$
\text { Yes }
$$

No

Who administered the naloxone (the last time you overdosed)? ${ }^{c}$

\begin{tabular}{llll} 
A police officer & $4(19.0)$ & $3(75.0)$ & $1(25.0)$ \\
An ambulance official & $2(9.5)$ & $2(100.0)$ & $0(0.0)$ \\
A friend & $3(14.3)$ & $2(66.7)$ & $1(33.3)$ \\
A parent or relative & $1(4.8)$ & $0(0.0)$ & $1(100.0)$ \\
Someone else & $2(9.5)$ & $2(100.0)$ & $0(0.0)$ \\
\hline
\end{tabular}

Note: "Recent overdoses" were those that occurred within the last 6 months ${ }^{a}$ Not all columns add to $100 \%$ due to missing values

${ }^{b}$ Of those who had experienced an overdose in the past 6 months and were not alone when they overdosed

'Of those who had experienced an overdose in the past 6 months and were treated with naloxone

history of overdose (36.6 versus $9.7 \%$ for black and mixed/other race participants, $p<0.001$ ).

A trend emerged in which participants with more extensive drug use profiles were (proportionally) more aware of the RIGSL. For example, of the 59 NMPO users who had ever injected drugs, $72.9 \%$ were aware of the RIGSL, whereas only $33.3 \%$ of non-injectors were aware of the RIGSL $(p<0.001)$. This trend held for heroin use, with $64.7 \%$ of participants who had tried heroin and only $31.0 \%$ who had not tried heroin reporting awareness of the RIGSL $(p<0.001)$. Having ever experienced an overdose and having ever seen someone overdose were also both associated with awareness of the RIGSL (both $p<0.05$, see Table 1 ).

Several measures of harm reduction education (e.g., having ever heard of naloxone, knowing where naloxone could be obtained, and having ever administered naloxone) were significantly and positively associated with knowledge of the RIGSL (all $p<0.05$ ). In addition, the vast majority of participants (95.5\%) reported a willingness to call 911 in the event of an overdose-related emergency even if there were drugs at the scene. However, among the 189 NMPO users surveyed who reported willingness to call 911, only $46.0 \%$ were aware of the GSL, and knowledge of the GSL was not associated with a willingness to call 911 ( $p=0.729$ ).

The final explanatory multivariate model with the lowest AIC included the following covariates: history of injection drug use (APR $=1.29,95 \%$ CI 1.01-1.57, $p=$ $0.064)$, having heard of naloxone ( $\mathrm{APR}=1.88,95 \% \mathrm{CI}$ $1.28-2.49, p=0.071)$, and knowledge of where to obtain naloxone (APR $=1.73,95 \%$ CI 1.29-2.17, $p=0.002)$.

Lastly, among the 21 participants who experienced an opioid overdose within 6 months of completing the survey, 14 (66.7\%) were aware of the RIGSL. Of note, all six individuals who reported having an individual call 911 the last time they overdosed were aware of the RISGSL. However, we have no data indicating that the individuals who actually dialed 911 in response to these (six) particular overdose situations were aware of the RIGSL. Of the 12 individuals who reported naloxone being administered the last time they overdosed, 9 (75.0 \%) were aware of the RIGSL. Other reactions to individuals' most recent overdose stratified by knowledge of the RIGSL are shown in Table 2.

\section{Discussion}

In this study of young adult NMPO users in RI, knowledge of the RIGSL was moderately high but unevenly distributed across the study population. Despite this, participants reported nearly universal willingness to recruit 911 in the event of an opioid emergency. Knowledge of the RIGSL was less common among young NMPO users who had not used heroin, injected drugs, or witnessed or experienced an overdose.

Given these findings, it is possible that young adult NMPO users in RI first learn about the RIGSL after experiencing or witnessing an overdose. A second possible explanation is that harm reduction programs (which provide naloxone education, overdose training, and injection equipment) may educate their high-risk clientele about the protections afforded by GSLs. In fact, knowledge of where naloxone could be obtained was the strongest correlate of awareness of the RIGSL. Other covariates included in the final model (history of injection drug use, having heard of naloxone) also support the assertion that young NMPO users in RI (and likely also their opioid using peers) may currently be receiving education about the RIGSL through harm reduction outlets that provide naloxone and injection equipment.

Over $95 \%$ of the study participants reported willingness to call 911 in the event of an overdose, despite the fact that fear of arrest has historically been a primary 
reason for failing to contact emergency medical services during an overdose [25]. In RI, a recent study showed high levels of knowledge of RIGSL among police officers and near universal awareness of the protections afforded by the RIGSL among those who received opioid overdose training [26]. It is possible that these educational and outreach efforts with law enforcement personnel, and as well considerable media coverage encouraging individuals to contact emergency services in the event of an overdose, have led to a high level of willingness to call 911 in this setting.

In light of these findings, it is important to consider how the RIGSL could be made more effective, even when NMPO-using young adults are aware of the GSL. For example, the physiological consequences of opioid overdose may render individuals who overdose alone physically unable to recruit help or emergency services. It follows that the effectiveness of the RIGSL likely depends, in part, on the degree to which individuals engage in social (or monitored) NMPO use. Of the 21 participants who reported a recent overdose, 4 (19.0\%) were alone. Thus, interventions may be needed to encourage young adults who use prescription opioids non-medically to avoid doing so alone, in addition to campaigns promoting the protections afforded by GSLs.

A recent report showed that targeting naloxone education programs to nearly 3000 bystanders (individuals who might have contact with NMPO and heroin users) successfully decreased the rate of fatal opioid overdose in 19 towns across Massachusetts [3]. Given these results, it may be prudent to target education about the RIGSL to bystanders (i.e., close friends and family of young NMPO users), as well as to young NMPO users themselves, in order to improve the efficacy of the RIGSL.

This analysis should be considered in light of several limitations. First, underreporting of socially undesirable behaviors (e.g., ever using heroin, ever injecting, being unwilling to call 911 in response to a potentially fatal overdose) is possible. Second, the small sample size impeded robust examination of the relationship between knowledge of the RIGSL and the actions participants took in response to recent overdoses. Finally, although multiple online and field-based methods were used to recruit study participants, the findings may not necessarily be generalizable to all young adult NMPO users in RI. Unfortunately, to our knowledge, no other studies have examined NMPO use among young adults in RI or other states in the New England region. Future studies are needed to confirm whether this sample is representative of the target population.

In sum, we observed moderate levels of awareness of a GSL among young adults who use prescription opioids non-medically in RI. Targeted harm reduction education (concerning the RIGSL but also general overdose prevention and response training) may be needed to address a vulnerable population of NMPO users who have not initiated injection drug or heroin use. Additional research is needed to determine how the effectiveness of GSLs could be improved to prevent overdose deaths among young adults.

\section{Abbreviations}

GSL, Good Samaritan Law; NMPO, non-medical prescription opioid; RI, Rhode Island; RIGSL, Rhode Island's Good Samaritan Law

\section{Acknowledgements}

We would like to thank the study participants and current and past RAPiDS researchers and staff, as well as Jesse Yedinak and Beth Elston, for their research and administrative assistance.

\section{Funding}

The RAPiDS project is supported by the US National Institute on Drug Abuse (R03-DA037770). Brandon Marshall is supported by a Henry Merrit Wriston Fellowship from Brown University. The funders had no role in the design of the study, the collection, analysis, and interpretation of data, or the decision to submit the manuscript for publication.

\section{Availability of data and materials}

The data supporting the conclusions of this article were collected as part of a pilot study of non-medical prescription opioid drug use among young adults in Rhode Island. The Center for Population Health and Clinical Epidemiology, located at the Brown University School of Public Health, maintains a de-identified analysis dataset. Requests for data on which the conclusions of this manuscript rely can be forwarded to the corresponding author, Dr. Brandon DL Marshall (brandon_marshall@brown.edu). All the data and associated documentation will be made available to users only under a data-sharing agreement that provides for (1) a commitment to using the data only for research purposes and not to identify any individual participant and (2) a commitment to securing the data using appropriate computer technology.

\section{Authors' contributions}

TIE designed and performed the analysis and wrote and edited the manuscript. SEH, MAC, and TCG edited the manuscript. BDLM designed the analysis, wrote and edited the manuscript, and obtained the funding for this research. All authors approved the final manuscript.

\section{Competing interests}

The authors declare that they have no competing interests.

\section{Consent for publication}

Not applicable.

\section{Ethics approval and consent to participate}

As stated in the Methods section, this study received approval from a research ethics committee, the Brown University Institutional Review Board (IRB \#1403001006), and conforms to the standards outlined in the Declaration of Helsinki. Participants voluntarily signed informed consent forms prior to completing a confidential survey.

\section{Author details}

'Department of Epidemiology, Brown University School of Public Health, 121 South Main Street, Box G-S-121-2, Providence, RI 02912, USA. ²Division of Adolescent/Young Adult Medicine, Department of Medicine, Boston Children's Hospital, 333 Longwood Avenue, Boston, MA 02115, USA. ${ }^{3}$ Department of Pediatrics, Harvard Medical School, 25 Shattuck Street, Boston, MA 02115, USA. " Department of Health Policy and Management, Harvard T. H. Chan School of Public Health, 677 Huntington Ave, Boston, MA 02115, USA. ${ }^{5}$ Department of Quantitative Health Sciences and Center for Health Policy and Research, University of Massachusetts Medical School, 55 Lake Ave North, Worcester, MA 01605, USA. ${ }^{6}$ Department of Emergency Medicine, Boston University School of Medicine, 771 Albany Street, Room 1208, Boston, MA 02118, USA. ${ }^{7}$ Rhode Island Hospital, The Warren Alpert School of Medicine of Brown University, 55 Claverick Street, Providence, RI 02903, USA. 
Received: 4 May 2016 Accepted: 8 July 2016

Published online: 26 July 2016

\section{References}

1. Compton WM, Jones CM, Baldwin GT. Relationship between nonmedical prescription-opioid use and heroin use. N Engl J Med [Internet]. 2016;374: 154-63. Available from: http://www.ncbi.n/m.nih.gov/pubmed/26760086. Accessed 9 Mar 2016.

2. Centers for Disease Control and Prevention (CDC). Community-based opioid overdose prevention programs providing naloxone-United States, 2010. MMWR Morb Mortal Wkly Rep [Internet]. 2012;61:101-5. [cited 2016 Mar 9]. Available from: http://www.ncbi.nlm.nih.gov/pubmed/22337174.

3. Walley AY, Xuan Z, Hackman HH, Quinn E, Doe-Simkins M, Sorensen-Alawad A, et al. Opioid overdose rates and implementation of overdose education and nasal naloxone distribution in Massachusetts: interrupted time series analysis. BMJ [Internet]. 2013;346:f174. [cited 2016 Mar 9]. Available from: http://www.bmj.com/cgi/doi/10.1136/bmj.f174.

4. Poon SJ, Greenwood-Ericksen MB, Gish RE, Neri PM, Takhar SS, Weiner SG, et al. Usability of the Massachusetts prescription drug monitoring program in the emergency department: a mixed methods study. Acad Emerg Med [Internet]. 2016. [cited 2016 Mar 9]. Available from: http://www.ncbi.nlm.nih. gov/pubmed/26806310

5. Thomas CP, Kim M, Nikitin RV, Kreiner P, Clark TW, Carrow GM. Prescriber response to unsolicited prescription drug monitoring program reports in Massachusetts. Pharmacoepidemiol. Drug Saf [Internet]. 2014;23:950-7. [cited 2016 Mar 9]. Available from: http://www.ncbi.nlm.nih.gov/pubmed/24920376.

6. National Conference of State Legislatures. Drug overdose immunity and Good Samaritan Laws [Internet]. 2015. [cited 2016 Mar 9]. Available from: http://www.ncsl.org/research/civil-and-criminal-justice/drug-overdoseimmunity-good-samaritan-laws.aspx\#Calling 911.

7. The Good Samaritan Overdose Prevention Act [Internet]. [cited 2016 Jun 28]. Available from: http://webserver.rilin.state.ri.us/Statutes/TITLE21/21-28.8/ INDEX.HTM.

8. Hadland SE, DeBeck K, Kerr T, Feng C, Montaner JS, Wood E. Prescription opioid injection and risk of hepatitis $C$ in relation to traditional drugs of misuse in a prospective cohort of street youth. BMJ Open [Internet]. 2014;4:e005419. [cited 2016 Mar 9]. Available from: http://www.ncbi.nlm.nih.gov/pubmed/25052173.

9. Mateu-Gelabert $P$, Guarino $H$, Jessell L, Teper A. Injection and sexual HIV/ HCV risk behaviors associated with nonmedical use of prescription opioids among young adults in New York City. J Subst Abuse Treat [Internet]. 2015; 48:13-20. [cited 2016 Mar 9]. Available from: http://linkinghub.elsevier.com/ retrieve/pii/S0740547214001172.

10. Miech R, Johnston L, O'Malley PM, Keyes KM, Heard K. Prescription opioids in adolescence and future opioid misuse. Pediatrics [Internet]. 2015;136: e1169-77. [cited 2016 Mar 9]. Available from: http://www.ncbi.nlm.nih.gov/ pubmed/26504126.

11. Carlson RG, Nahhas RW, Martins SS, Daniulaityte R. Predictors of transition to heroin use among initially non-opioid dependent illicit pharmaceutical opioid users: a natural history study. Drug Alcohol Depend [Internet]. 2016; 160:127-34. [cited 2016 Apr 23]. Available from: http://www.ncbi.nlm.nih. gov/pubmed/26785634.

12. Cerdá M, Santaella J, Marshall BDL, Kim JH, Martins SS. Nonmedical prescription opioid use in childhood and early adolescence predicts transitions to heroin use in young adulthood: a national study. J Pediatr [Internet]. 2015;167:605-12.e2. [cited 2016 Mar 20]. Available from: http:// linkinghub.elsevier.com/retrieve/pii/S002234761500459X.

13. Lankenau SE, Wagner KD, Silva K, Kecojevic A, Iverson E, McNeely M, et al. Injection drug users trained by overdose prevention programs: responses to witnessed overdoses. J Community Health [Internet]. 2013;38:133-41. [cited 2016 Mar 20]. Available from: http://www.ncbi.nlm.nih.gov/pubmed/22847602.

14. Bohnert ASB, Tracy M, Galea S. Characteristics of drug users who witness many overdoses: implications for overdose prevention. Drug Alcohol Depend [Internet]. 2012;120:168-73. [cited 2016 Mar 10]. Available from: http://linkinghub.elsevier.com/retrieve/pii/ S0376871611003371.

15. Islam MM, Day CA, Conigrave KM. Harm reduction healthcare: from an alternative to the mainstream platform? Int J Drug Policy. 2010;21(2):131-3.

16. Gaston RL, Best D, Manning V, Day E. Can we prevent drug related deaths by training opioid users to recognise and manage overdoses? Harm Reduct
J [Internet]. 2009;6:26. [cited 2016 Mar 10]. Available from: http://www.ncbi. nlm.nih.gov/pubmed/19781073.

17. Piper TM, Stancliff S, Rudenstine S, Sherman S, Nandi V, Clear A, et al. Evaluation of a naloxone distribution and administration program in New York City. Subst Use Misuse [Internet]. 2008;43:858-70. [cited 2016 Mar 20]. Available from: http://www.tandfonline.com/doi/full/10.1080/ 10826080701801261.

18. Albert S, Brason FW, Sanford CK, Dasgupta N, Graham J, Lovette B. Project Lazarus: community-based overdose prevention in rural North Carolina. Pain Med [Internet]. 2011;12:S77-85. [cited 2016 Mar 20]. Available from: http:// painmedicine.oxfordjournals.org/cgi/doi/10.1111/j.1526-4637.2011.01128.x.

19. Green TC, Zaller N, Palacios WR, Bowman SE, Ray M, Heimer R, et al. Law enforcement attitudes toward overdose prevention and response. Drug Alcohol Depend [Internet]. 2013;133:677-84. [cited 2016 Mar 4]. Available from: http://www.ncbi.nlm.nih.gov/pubmed/24051061.

20. Frank D, Mateu-Gelabert P, Guarino H, Bennett A, Wendel T, Jessell $L$, et al. High risk and little knowledge: overdose experiences and knowledge among young adult nonmedical prescription opioid users. Int J Drug Policy [Internet]. 2015;26:84-91. [cited 2016 Mar 9]. Available from: http:// linkinghub.elsevier.com/retrieve/pii/S0955395914002060.

21. Guarino H, Marsch LA, Deren S, Straussner SLA, Teper A. Opioid use trajectories, injection drug use, and hepatitis $C$ virus risk among young adult immigrants from the former Soviet Union living in New York City. J Addict Dis [Internet]. 2015;34:162-77. [cited 2016 Jun 28]. Available from: http:// www.ncbi.nlm.nih.gov/pubmed/26132715.

22. Kecojevic A, Silva K, Sell RL, Lankenau SE. Prescription drug misuse and sexual risk behaviors among young men who have sex with men (YMSM) in Philadelphia. AIDS Behav. [Internet] NIH Public Access. 2015;19:847-56. [cited 2016 Jun 28]. Available from: http://www.ncbi.nlm.nih.gov/pubmed/ 25240627.

23. Lima VD, Harrigan R, Murray M, Moore DM, Wood E, Hogg RS, et al. Differential impact of adherence on long-term treatment response among naive HIV-infected individuals. AIDS [Internet]. 2008;22:2371-80. [cited 2016 Mar 31]. Available from: http://www.ncbi.nlm.nih.gov/pubmed/18981777.

24. Harrell FE. Regression modeling strategies [Internet]. New York: Springer New York; 2001. [cited 2016 Mar 31]. Available from: http://link.springer. com/10.1007/978-1-4757-3462-1.

25. Tobin KE, Davey MA, Latkin CA. Calling emergency medical services during drug overdose: an examination of individual, social and setting correlates. Addiction [Internet]. 2005;100:397-404. Blackwell Science Ltd; [cited 2016 Apr 25]. Available from: http://doi.wiley.com/10.1111/j.1360-0443.2005.00975.x.

26. Saucier CD, Zaller N, Macmadu A, Green TC. An initial evaluation of law enforcement overdose training in Rhode Island. Drug Alcohol Depend. 2016;162:211-8

\section{Submit your next manuscript to BioMed Central and we will help you at every step:}

- We accept pre-submission inquiries

- Our selector tool helps you to find the most relevant journal

- We provide round the clock customer support

- Convenient online submission

- Thorough peer review

- Inclusion in PubMed and all major indexing services

- Maximum visibility for your research

Submit your manuscript at www.biomedcentral.com/submit 